\title{
The Actin Bundling Protein Fascin-1 as an ACE2-Accessory Protein
}

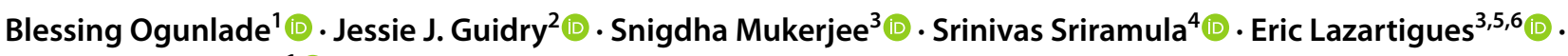 \\ Catalin M. Filipeanu ${ }^{1}$
}

Received: 17 June 2020 / Accepted: 20 August 2020 / Published online: 31 August 2020

(c) Springer Science+Business Media, LLC, part of Springer Nature 2020

\begin{abstract}
We have previously shown that angiotensin-converting enzyme 2 (ACE2), an enzyme counterbalancing the deleterious effects of angiotensin type 1 receptor activation by production of vasodilatory peptides Angiotensin (Ang)-(1-9) and Ang(1-7), is internalized and degraded in lysosomes following chronic Ang-II treatment. However, the molecular mechanisms involved in this effect remain unknown. In an attempt to identify the accessory proteins involved in this effect, we conducted a proteomic analysis in ACE2-transfected HEK293T cells. A single protein, fascin-1, was found to differentially interact with ACE2 after Ang-II treatment for $4 \mathrm{~h}$. The interactions between fascin-1 and ACE2 were confirmed by confocal microscopy and co-immunoprecipitation. Overexpression of fascin-1 attenuates the effects of Ang-II on ACE2 activity. In contrast, downregulation of fascin-1 severely decreased ACE2 enzymatic activity. Interestingly, in brain homogenates from hypertensive mice, we observed a significant reduction of fascin-1, suggesting that the levels of this protein may change in cardiovascular diseases. In conclusion, we identified fascin- 1 as an ACE2-accessory protein, interacting with the enzyme in an Ang-II dependent manner and contributing to the regulation of enzyme activity.
\end{abstract}

Keywords Angiotensin-converting enzyme $2 \cdot$ Fascin-1 $\cdot$ Actin bundling protein $\cdot$ Internalization $\cdot$ Angiotensin type 1 receptor

Catalin M. Filipeanu

Catalin.Filipeanu@Howard.edu

1 Department of Pharmacology, College of Medicine, Howard University, 520 W St., NW, Washington, DC 20059, USA

2 Department of Biochemistry and Molecular Biology, Louisiana State University Health Sciences Center, New Orleans, LA 70112, USA

3 Department of Pharmacology \& Experimental Therapeutics, Louisiana State University Health Sciences Center, New Orleans, LA 70112, USA

4 Department of Pharmacology and Toxicology, Brody School of Medicine at East Carolina University, 600 Moye Blvd, Greenville, NC 27834, USA

5 Cardiovascular Center of Excellence, Louisiana State University Health Sciences Center, New Orleans, LA 70112, USA

6 Southeast Louisiana Veterans Health Care Systems, New Orleans, LA 70119, USA

\section{Introduction}

The renin-angiotensin system (RAS) represents one of the most important therapeutic targets for the treatment of cardiovascular diseases. During the last 20 years, angiotensinconverting enzyme 2 (ACE2) has been shown to contribute to the maintenance of normal cardiovascular function. Its major role includes hydrolysis of angiotensin (Ang)-I and Ang-II to vasodilatory peptides Ang-(1-9) and Ang-(1-7), respectively (Donoghue et al. 2000; Vickers et al. 2002; Xu et al. 2011). Ang-(1-9) and Ang-(1-7) acting putatively through Ang-II type 2 receptor $\left(\mathrm{AT}_{2} \mathrm{R}\right)$ and Mas1 receptor (Mas1R) (Filipeanu and Lazartigues 2020; Karnik et al. 2017; Mendoza-Torres et al. 2018) attenuate the proliferative and contractile effects of $\mathrm{AT}_{1} \mathrm{R}$ activation by Ang-II and ultimately opposing the development of hypertension (Xu et al. 2017, 2011). Recently, ACE2 was also identified as a "receptor" for the SARS-CoV-2 virus responsible for the COVID-19 pandemic. ACE2 contains a single HEXXH zinc-binding domain which is homologous to one of the active sites of ACE and shares $40 \%$ overall identity to ACE 
but its enzymatic activity is not sensitive to typical ACE inhibitors (Donoghue et al. 2000; Vickers et al. 2002).

Overexpression of ACE2 has been shown to prevent the development of hypertension (Feng et al. 2010, 2008), whereas its downregulation leads to chronic increase in blood pressure levels (Deshotels et al. 2014; Xu et al. 2011). ACE2 can also be shed and enter the circulation under action of metalloproteases such as ADAM17 (de Queiroz et al. 2015; Xu et al. 2017). However, hydrolysis of Ang-II is mediated in large part by cellular ACE2 (Mukerjee et al. 2019; Pedersen et al. 2015) and requires the carboxypeptidase to be present on the cell surface (Deshotels et al. 2014). Our group originally demonstrated that Ang-II induces ACE2 internalization and degradation into lysosomes through an Ang-II type 1 receptor $\left(\mathrm{AT}_{1} \mathrm{R}\right)$-dependent mechanism and this process leads to a decrease in the expression levels and activity of the enzyme (Deshotels et al. 2014). However, the molecular mechanisms controlling ACE2 trafficking to lysosomes remain unclear.

Intracellular protein trafficking is a highly regulated process controlled by interactions with specific accessory proteins (also named molecular chaperones) (Ciruela et al. 2010; Filipeanu 2015; Rodemer and Haucke 2008). Indeed, $\mathrm{AT}_{1} \mathrm{R}$-associated protein (ATRAP) was shown to interact with $\mathrm{AT}_{1} \mathrm{R}$ (Lopez-Ilasaca et al. 2003) and microtubuleassociated tumor suppressor gene (MTUS1)/ $\mathrm{AT}_{2} \mathrm{R}$ interacting protein (ATIP) with $\mathrm{AT}_{2} \mathrm{R}$ (Bozgeyik et al. 2017). Interestingly, at least one MTUS1/ATIP isoform, ATIP3a was reported to be co-localized with microtubules, which form the cell cytoskeleton (Bozgeyik et al. 2017). No such proteins are yet known for ACE and ACE2, but because both enzymes are internalized from plasma membrane to endosomes (Deshotels et al. 2014; Lucero et al. 2010), the availability of such accessory proteins can be predicted. Identification of these binding partners may offer additional pharmacological and therapeutic tool to target RAS activity and SARS-CoV-2 infection. Therefore, the aim of the present work was to identify and characterize accessory proteins involved in ACE2 internalization.

\section{Materials and Methods}

\section{Materials}

Plasmids used in this study were obtained as follows: Human GFP-tagged ACE2 was from Origene, human fascin-1 (FusionRed-Fascin-C-10) was a gift from Michael Davidson (Addgene plasmid \# 56117), human HA-tagged $\mathrm{AT}_{1} \mathrm{R}$ was a gift from Dr. Guangyu Wu (Medical College of Georgia). Cell culture medium, antibiotics, Lipofectamine 2000, and fetal bovine serum (FBS) were from Thermofisher; normal donkey serum was from Sigma-Aldrich; antibodies against
ACE2 (sc-390851), GFP (sc-9996), $\beta$-actin (sc-8432) and fascin-1 (sc-46675), as well as lentiviral shRNA particles against fascin-1 (sc-35359-V) were obtained from Santa Cruz Biotechnology. The $\alpha$-tubulin antibody (T6199) and deoxycorticosterone acetate (DOCA) were from SigmaAldrich. HEK293T cells (ATCC CRL-3216) were used in this study between passage number 4 and 27 .

\section{Cell Culture and Transfection}

HEK293T were cultured in Dulbecco's modified Eagle's medium containing $10 \%$ fetal bovine serum, 10 units $/ \mathrm{mL}$ penicillin, and $100 \mu \mathrm{g} / \mathrm{mL}$ streptomycin. The cells were plated in 6-well plates and transfected at $\sim 80 \%$ confluency with $0.5 \mu \mathrm{g}$ of ACE2-GFP, $0.5 \mu \mathrm{g} \mathrm{AT} \mathrm{A}_{1} \mathrm{R}-\mathrm{HA}$, and/or $0.5 \mu \mathrm{g}$ fascin-1 using Lipofectamine 2000 reagent in Dulbecco's modified Eagle's medium with no antibiotics and no fetal bovine serum. After $6 \mathrm{~h}$, the cells were cultured in full medium for $48 \mathrm{~h}$, serum starved for another $24 \mathrm{~h}$ before performing the experiments.

\section{Confocal Microscopy}

For confocal microscopy, HEK293T cells were grown on coverslips pre-coated with poly-L-lysine in 6-well plates and transfected. The cells were fixed with a $4 \%$ paraformaldehyde $/ 4 \%$ sucrose mixture in PBS for $15 \mathrm{~min}$ and stained with 4, 6-diamidino-2-phenylindole for $5 \mathrm{~min}$. For plasma membrane staining, cells were incubated with WGA (Thermofisher) prior to fixation. The cells were permeabilized in PBS and blocked with normal donkey serum. The cells were then incubated with antibodies dilution of 1:1000 overnight at $4{ }^{\circ} \mathrm{C}$. After washing with PBS $(3 \times 5 \mathrm{~min})$, the cells were incubated with Alexa Fluor 594-labeled secondary antibody (1:1000 dilution) for $1 \mathrm{~h}$ at room temperature. Fluorescent images of fixed samples were captured using a Nikon Ti-EPFS inverted spinning-disk confocal microscope equipped with a $60 \times 1.4$ NA Plan Apo Lambda objective.

\section{Western Blotting}

Transfected cells were collected in loading buffer (1X Laemmle buffer) then samples were separated by $10 \%$ sodium dodecyl sulfate-polyacrylamide gel electrophoresis, followed by transfer onto polyvinylidene fluoride (PVDF) membranes. The membranes were then exposed to specific primary and secondary antibodies then protein levels were visualized using LiCor digital blot scanner (LiCor bioscience) and quantified using LiCor software.

For mouse samples, hypothalamic proteins $(30-50 \mu \mathrm{g})$ were processed for Western blotting as previously described,(Xia et al. 2009) using a mouse anti-fascin monoclonal primary antibody (Cell Signal Technology 54545S, 
$1: 1000)$ and a goat anti-mouse IgG, HRP conjugate (SigmaAldrich A9917, 1:5000) as secondary antibody. $\alpha$-tubulin (Sigma-Aldrich T6199, 1:10,000) was used as a loading control.

\section{Co-immunoprecipitation}

The cells were lysed in a co-immunoprecipitation buffer (50 mM Tris-HCl, pH 7.4, 150 mM NaCl, 1\% NP-40, 0.5\% sodium deoxycholate, $0.1 \%$ sodium dodecyl sulfate and Complete Mini protease inhibitor cocktail) two days after transfection. The samples were centrifuged (13,200 rpm) and the supernatant was collected and subsequently incubated with $50 \mu \mathrm{L}$ of protein $\mathrm{A} / \mathrm{G}$ Sepharose at $4{ }^{\circ} \mathrm{C}$ overnight, followed by incubation with anti-GFP antibodies $\left(1 \mu \mathrm{g} / \mathrm{mg}\right.$ protein) at $4{ }^{\circ} \mathrm{C}$ for $4 \mathrm{~h}$. The protein complexes were recovered with $50 \mu \mathrm{L}$ protein A/G Sepharose and further processed by Western blotting.

\section{Determination of ACE2 Activity}

Transfected HEK293T cells were extracted in ACE2 reaction buffer $(0.5 \%$ Triton X-100 in ACE2 reaction buffer containing $1 \mathrm{M} \mathrm{NaCl}, 0.5 \mathrm{mM} \mathrm{ZnCl}_{2}, 75 \mathrm{mM}$ TrisHCl and $100 \mu \mathrm{M}$ Mca-YVADAPK (Dnp, from Anaspec Inc, Freemont, CA) and were sonicated $4 \times 5 \mathrm{~s}$ and centrifuged at $20,817 \times g$ at $4{ }^{\circ} \mathrm{C}$ for $10 \mathrm{~min}$. The supernatant was recovered, and the protein concentration was determined by Bradford method. Each reaction used $10 \mu \mathrm{g}$ of cell lysates. Fluorescence emission was detected at $405 \mathrm{~nm}$, after excitation at $320 \mathrm{~nm}$ in a Biotek Cytation 3 spectrometer, and the slope of fluorescence development was calculated between 10 and $120 \mathrm{~min}$ of incubation. Blank values were obtained with extraction buffer only and were subtracted from the hydrolysis rates of the sample extracts. Hydrolysis rates were quantified as fluorescence units per minute per amount of protein and are reported as percentage of the values obtained in control (untreated) cells. The control values in ACE2-transfected cells amounted to $21,545 \pm 2721$ arbitrary units (a.u.).

\section{Protein Interaction with ACE2 Identification by Liquid Chromatography-Mass Spectrometry Analysis}

The cells were transfected and processed as above, followed by treatment with Ang-II for $4 \mathrm{~h}$. Cellular lysates were obtained as in co-immunoprecipitation experiments and subsequently two-dimensional difference gel electrophoresis labeling and analysis was performed as previously described (Filipeanu 2015). Fluorophore-labeled protein gels were scanned using a Typhoon 9400 Variable Mode Imager (GE Healthcare, Piscataway, NJ) at $100 \mu \mathrm{m}$ resolution. CyDye (GE Healthcare) difference gel electrophoresis labeling was detected using the following wavelength settings: $\mathrm{Cy} 2$, excitation $488 \mathrm{~nm}$, emission $520 \mathrm{~nm}$; Cy3, excitation $532 \mathrm{~nm}$, emission $580 \mathrm{~nm}$; and Cy5, excitation $633 \mathrm{~nm}$, emission $670 \mathrm{~nm}$. Spot detection and quantification were performed using the DeCyder differential analysis software DIA, version 5.0 (GE Healthcare) and individual gels were imported into DeCyder biologic variation analysis for $t$ test analysis. Spots of interest were determined to have a difference greater than $50 \%$ or a $t$ test $p$ value of less than 0.05 . Gels were then post stained with Sypro Ruby (Bio-Rad), and images were captured again using the Typhoon 9400 Imager (GE Healthcare). Spots of interest were excised and trypsin (Promega, Madison, WI) digested using the automated Spot Handling Workstation (GE Healthcare).

The mass spectrometry (MS) data were acquired using a Thermo LTQ-XL linear ion trap mass spectrometer (Thermo Fisher Scientific, Waltham, MA) coupled to an Eksigent nanoLC (Dublin, CA). Peptide samples were loaded onto a Dionex C18 PepMap 100 trap column with dimensions of $300 \mu \mathrm{m}$ (i.d.) $\times 5 \mathrm{~mm}$ (Dionex, Sunnyvale, CA) and were separated by a reversed-phase $\mathrm{C} 18$ PicoFrit emitter with dimensions of $75 \mu \mathrm{m}$ (i.d.) $\times 10 \mathrm{~cm}$ (bed length) with $15 \mu \mathrm{m}$ tip size (New Objective, Woburn, MA). Peptides were loaded at $500 \mathrm{~nL} / \mathrm{min}$ using a mobile phase of $2 \%$ acetonitrile and $0.1 \%$ formic acid and then eluted using a gradient of $5-40 \%$ acetonitrile and $0.1 \%$ formic acid over $16 \mathrm{~min}$, with a ramp to $60 \%$ acetonitrile and $0.1 \%$ formic acid for $10 \mathrm{~min}$, and finally a ramp to $95 \%$ acetonitrile and $0.1 \%$ formic acid for $10 \mathrm{~min}$. A top five data-dependent scan strategy was used. The MS1 scan range was between m/z 300 and 2000. The top most abundant peptides in this MS1 scan were chosen for MS/MS. The MS/MS parameters were the following: isolation window set to $2 \mathrm{Da}, 35 \%$ relative collision energy, dynamic exclusion enabled with repeat count set to 1 , repeat duration of $30 \mathrm{~s}$, and an exclusion size of 100 with an exclusion duration of $20 \mathrm{~s}$. The MS data were then analyzed by Proteome Discoverer 1.4 (Thermo Fisher Scientific) against the Human SwissProt database (https:// www.uniprot.org/proteomes/).

\section{Animal Studies}

C57B16/J male mice (10-12 weeks old, $n=3$ /group) were anesthetized with isoflurane (2\%) and implanted subcutaneously with a DOCA $(1 \mathrm{mg} / \mathrm{g}$ body weight $)$ pellet and switched to a $1 \% \mathrm{NaCl}$ drinking solution, as described previously (Sriramula and Lazartigues 2017). After 3 weeks, mice were euthanized and the hypothalamus was dissected for protein extraction and Western blotting analysis, as mentioned above. All procedures conformed to the National Institutes of Health Guide for the Care and Use of Laboratory Animals and were approved by the Louisiana State 
University Health Sciences Center (\#3450) Institutional Animal Care and Use Committee.

\section{Statistical Analysis}

Each experiment was run in triplicate and repeated at least in three different passages. Data are presented as means \pm S.E.M. Statistical analysis was performed using one-way ANOVA, followed by the Tukey post-analysis and $p<0.05$ was considered as statistically significant.

\section{Results}

To identify new proteins interacting with ACE2, we performed a proteomic experiment in ACE2-transfected HEK293T cells. From the two-dimensional difference gel electrophoresis, seven spots appeared different between control and Ang-II-treated cells (100 nM, 4 h, Fig. 1a). However, after trypsin digestion and mass spectrometry analysis, we found that all these spots identified a single protein, namely fascin-1 (Fig. 1b). The different spots represent electronegative shifts caused by isoelectric focusing point changes due to post-translational modifications and most likely represent phosphorylation differences. Known phosphorylation sites for Fascin-1 include Serine-38, Serine-39, Serine-127, Serine-234, Threonine-239, and Threonie-403.
To confirm that indeed ACE2 interacts with fascin-1, we first performed co-localization experiments by confocal microscopy. In HEK293T cells co-transfected with GFP-tagged ACE2, HA-AT ${ }_{1}$ R, FusionRed-Fascin-1, we found that in control conditions ACE2 and fascin- 1 are colocalized at the plasma membrane level (Fig. 2a, top panel). However, after treatment with Ang-II (100 nM, 4 h), both proteins displayed perinuclear localization, but very little, if any, co-localization. No co-localization between ACE2 and fascin-1 was observed in absence of $\mathrm{AT}_{1} \mathrm{R}$ transfection (data not shown). Co-immunoprecipitation experiments demonstrated interactions between ACE2 and fascin-1 (Fig. 2b). Ang-II treatment $(100 \mathrm{nM}, 4 \mathrm{~h})$ did not have an effect on ACE2/fascin-1 interactions when immunoprecipitation was performed in cells without overexpression of fascin-1. However, in fascin-1-overexpressing cells, Ang-II treatment appears to decrease ACE2/fascin-1 interactions (Fig. 2b, last two lanes).

Next, we investigated if changes in cellular levels of fascin-1 are modulating ACE2 activity and expression levels. In untransfected HEK293T cells, ACE2 activity was below detection limit ( $328 \pm 645$ a.u., $n=6$ ). In HEK293T cells transfected only with ACE2 plasmid, ACE2 activity in control conditions amounted to $21,545 \pm 2721$ a.u., and, in agreement with our previous report (Deshotels et al. 2014), Ang-II treatment ( $100 \mathrm{nM}, 4 \mathrm{~h})$ did not have any effect $(21,381 \pm 2894$ a.u., $n=6)$. However, in cells
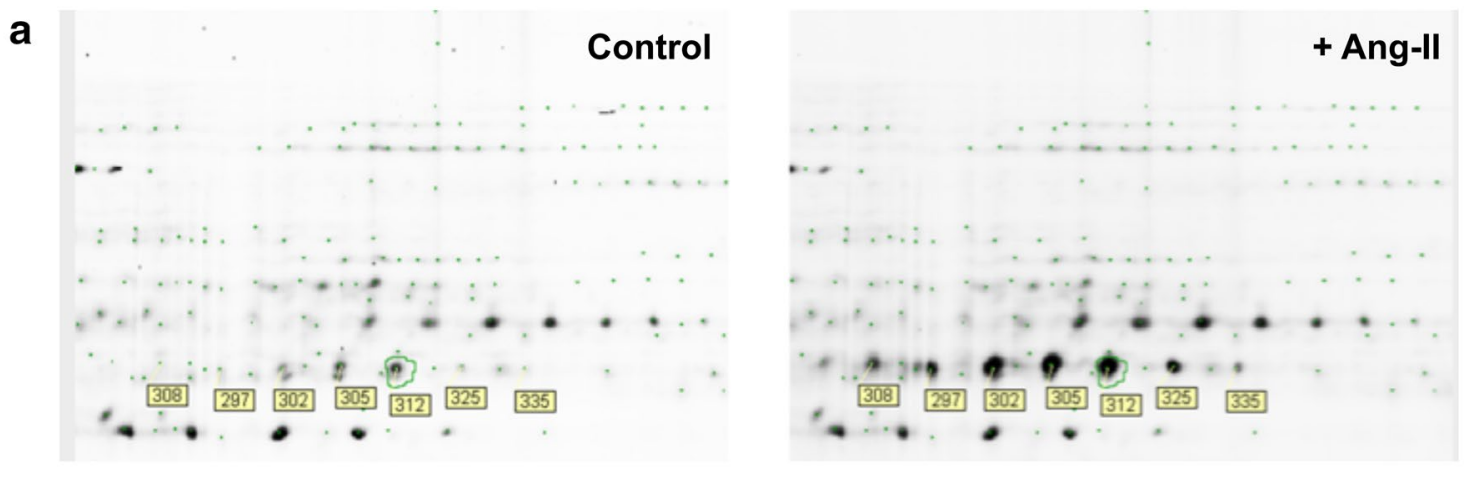

b

${ }^{1}$ MTANGTAEAVQIQFGLINCGNKYLTAEAFGFKVNASASSLKKKQIWTLEQPPDEAGSAAVCLRSHLGRYLAADKDG
NVTCEREVPGPDCRFLIVAHDDGRWSLQSEAHRRYGGTEDRLSCFAQTVSPAEKWSVHIAMH PQVNIYSVTRKRYA
HLSARPADEIAVDRDVPGVDSLITLAFQDQRYSVQTADHRFLRHDGRLVARPEPATGYTLEFSGKVAFRDCEGRY
LAPSGPSGTLKAGATKVGKDELFALEQSCAQVVLQAANERNVSTRQGMDLSANQDEETDQETFQLEIDRDTKKCAFR
THTGKYWTLTATGGVQSTASSKNASCYFDIEWRDRRITLRASNGKFVTSKKNGQLAASVETAGDSELFLMKLINRPI
IVFRGEHGFIGCRKVTGTLDANRSSYDVFQLEFNDAYNIKDSTGKYWTVGSDSAVTSSGDTPVDFFFECDYNKVA
$\overline{\text { IKVGGRYLKGDHAGVLKASAETVDPASLWEY493 }}$

Fig. 1 a Representative experiments showing 2-D gels for control (left) and Ang-II (100 nM, 4 h, right)-treated GFP-ACE2-transfected HEK293T cells. The indicated five spots were excised, picked, and digested, and identified by LTQ electrospray mass spectroscopy as described in Material and Methods. Similar results were obtained in two additional experiments. b Identification of fascin-1 as an accessory protein of ACE2. Full sequence of human fascin-1 (Q16658). Underlined peptides are those that were obtained by trypsinization and subsequent mass spectrometry 
a
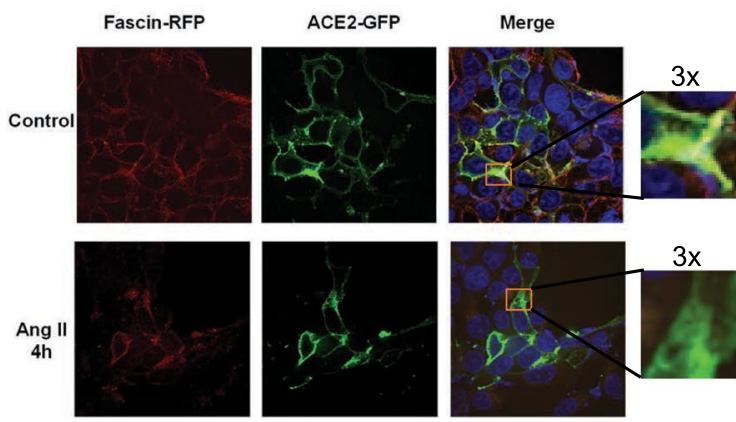

b

IP: GFP

IB: ACE2

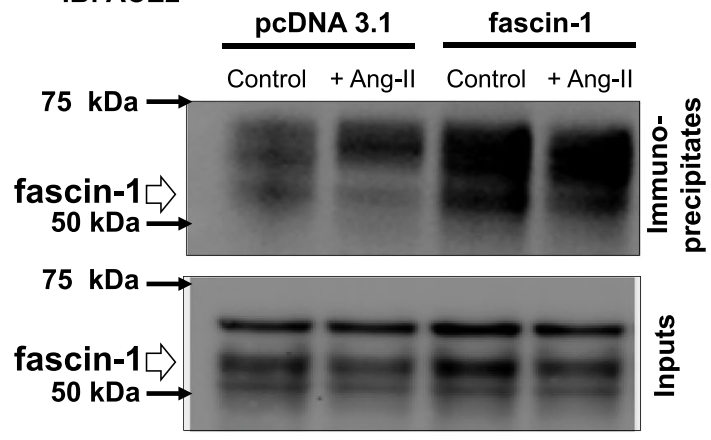

Fig. 2 a Co-localization of ACE2 and fascin-1 at subcellular level. HEK293T cells were co-transfected with GFP-tagged ACE2 and FusionRed-Fascin-C-10, processed as described in Material and Methods and examined by confocal microscopy. The far-right panels represent $\times 3$ magnification of the boxes shown the merged column. The pictures shown are representative from three independent transfections, each performed in triplicate. b Interactions between ACE2 and fascin-1 revealed by co-immunoprecipitation. HEK293T cells were processed as described in Material and Methods, subject to

co-transfected with $\mathrm{AT}_{1} \mathrm{R}$, Ang-II treatment (100 nM, $4 \mathrm{~h}$ ) induced a significant reduction of ACE2 activity $(22.1 \pm 9.2 \%$ from the values obtained in the untreated cells which was $20,120.11 \pm 6827.12$ a.u. $n=12$, Fig. 3a, $p<0.05)$. Overexpression of fascin-1 did not change basal ACE2 activity $(93.3 \pm 5.1 \%$, Fig. 3a), but prevented the effects of Ang-II on this parameter (98.1 $\pm 6.8 \%$, Fig. 3a). When we tested the effects of a longer Ang-II treatment (100 nM, $18 \mathrm{~h}$ ), which we have shown to induce ACE2 degradation in lysosomes (Carvalho-Galvao et al. 2018; Deshotels et al. 2014) in control cells, we found the the indicated treatments, lysed and immuno-precipitated with GFP antibody. GFP immuno-precipitates $(20 \mu \mathrm{g} / \mathrm{lane})$ were separated by $10 \%$ SDS-Page and the ACE2 levels were revealed by Western blotting. The band corresponding to the molecular weight of fascin-1 $(54.3 \mathrm{kDa})$ is indicated by white arrow. The inputs indicate $1 / 100$ from the initial cell lysates which were not subject to immunoprecipitation. The experiment shown is representative from three independent transfections

expected decrease in total cellular levels (Fig. 3b). However, in cells overexpressing fascin-1, this effect was abolished (Fig. 3b).

To confirm these results, we generated stable HEK293T cells with reduced fascin-1 cellular levels. Using puromycin selection after treatment with fascin-1 shRNA lentivirus, we generated a clone with $\sim 90 \%$ reduction in total fascin cellular levels (Fig. 4a). In these cells, we found a major reduction in ACE2 activity in basal conditions ( $75 \%$ inhibition) and treatment with Ang-II (100 nM, 4 h) did not produce a further inhibitory effect (Fig. 4b).

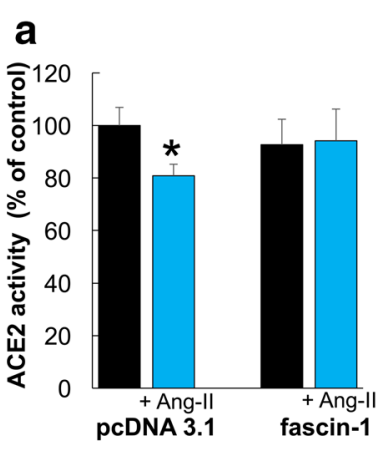

b

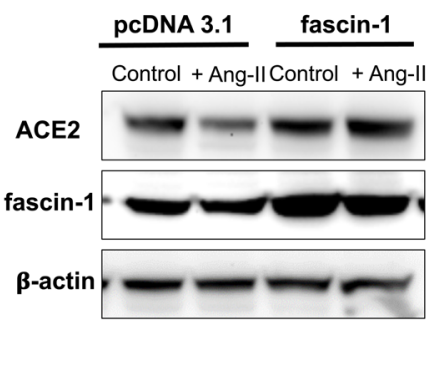

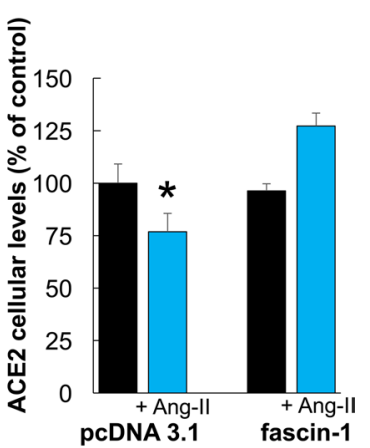

Fig. 3 a The effects of Ang-II on ACE2 activity in cells transfected with GFP-ACE2 $(0.5 \mu \mathrm{g})$ HA-AT1R $(0.5 \mu \mathrm{g})$ and co-transfected with control plasmid (pcDNA3.1) or fascin-1 plasmid (0.5 $\mu \mathrm{g}$ each). AngII treatment $(100 \mathrm{nM})$ lasted for $4 \mathrm{~h}$ and it was performed after starving the cells for $24 \mathrm{~h}$. The data are presented as \% from ACE2 activity determined in untreated cell, which was $20,120.11 \pm 6827.12$ a.u. Mean \pm S.E.M. from five independent transfections, each performed in triplicate. *Indicates statistical significant differences with $p<0.05$, using a two-tail Student's $t$ test. b The effects of Ang-II on total
ACE2 cellular levels are prevented by overexpression of fascin-1. Left: Representative blots showing the levels of ACE2, fascin-1, and $\beta$-actin in cells transfected with empty plasmid (pcDNA3.1, left) or fascin-1 (right), in the absence or presence of Ang-II (100 nM, $18 \mathrm{~h}$ ). Right: Quantification of the results obtained in three separate experiments performed in similar manner as in the left. ACE2 levels were quantified and normalized to $\beta$-actin and are expressed as percentage from the levels in control cells. $n=3$, *indicate $p<0.05$ vs. control 


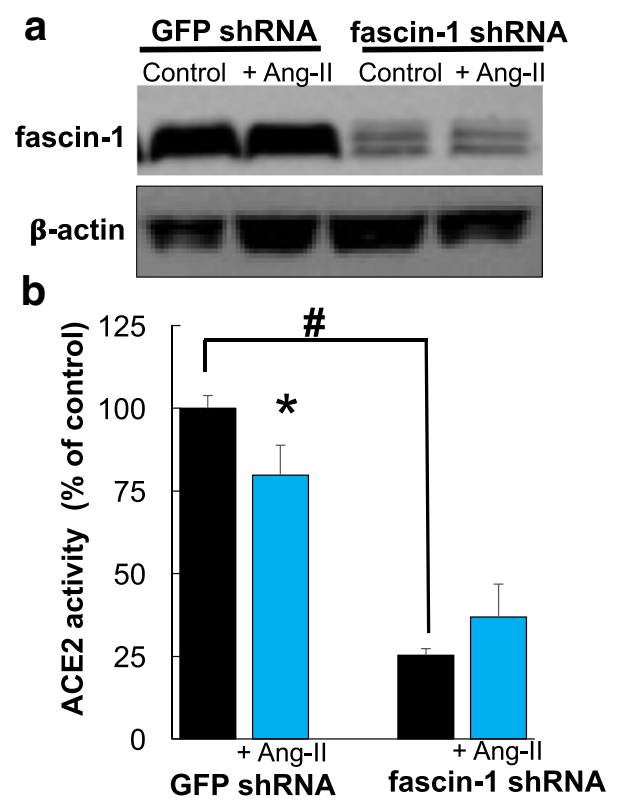

Fig. 4 a Downregulation of fascin-1 levels by lentiviral shRNA. Top: Fascin-1 cellular levels in puromycin-selected HEK293T clones treated with GFP-lentivirus (sc-108084, left two lanes) and fascin-1 shRNA lentivirus (sc-35359-V, right two lanes). These clones were selected using puromycin resistance as described in Material and Methods and subjected to Western blotting. Bottom: $\beta$-actin cellular levels in the same clones. Similar results were obtained in three independent experiments. b Reduced cellular fascin-1 levels diminished ACE2 activity. ACE2 activity was determined in stable HEK293T clones shown in a, obtained after treatment with GFP- or fascin-1 shRNA lentivirus in the absence or in presence of Ang-II (100 nM, 4 h). Mean \pm S.E.M., from two separate experiments, each performed in triplicate. *Indicate statistical significant differences with $p<0.05$, vs. control cells using a two-tail Student's $t$ test: \# indicates statistical significant decrease in ACE2 activity in fascin-1-downregulated cells using one-way ANOVA

To investigate whether these in vitro results can be related to pathological effects observed in vivo, we tested the levels of fascin-1 in brain homogenates from hypertensive mice. Mice undergoing a standard DOCA-salt protocol develop chronic hypertension within days which remains stable for several weeks (Xia et al. 2013). The hypothalamus of these DOCA-salt-treated hypertensive mice was assessed for fascin-1 protein expression. As shown in Fig. 5, fascin-1 levels were significantly reduced in chronically hypertensive mice.

\section{Discussion}

ACE2 was discovered in 2000, as a homologue of ACE with which it shares about $40 \%$ protein sequence identity in the catalytic domains (Donoghue et al. 2000; Vickers et al. 2002). However, in contrast to ACE, ACE2 hydrolyses Ang-I and Ang-II to produce the vasodilator peptides Ang-(1-9) and Ang-(1-7)(Ocaranza et al. 2014; Xu et al.
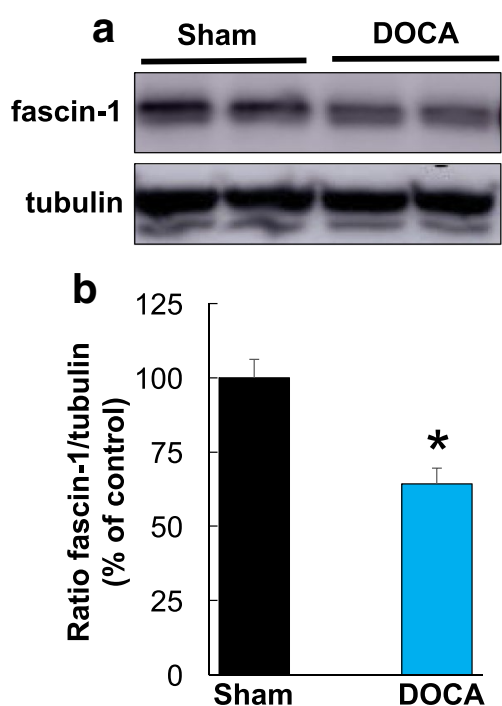

Fig. 5 a The effects of DOCA-salt-treatment on fascin-1 cellular levels in vivo. Hypothalamus proteins from sham and DOCA-salt-treated mice were analyzed by Western blotting. b Quantification of experiments $(n=3)$ shows that hypertension is associated with a reduction in fascin-1 levels. *Indicates statistical significance $(p<0.05)$ vs. sham group using a two-tail Student's $t$ test. Data are expressed as mean \pm S.E.M

2011), which counteracts the adverse effects of an overactive RAS (Feng et al. 2010, 2008). In addition, ACE2 is also the plasma membrane receptor for SARS-coronaviruses responsible for severe acute respiratory syndrome and COVID19, (da Costa et al. 2020; Giannis et al. 2020; Petrosillo et al. 2020). While ACE2 shedding has been demonstrated as a mechanism contributing to the development of hypertension (Carvalho-Galvao et al. 2018; Xia et al. 2013; Xu et al. 2017), much less is known about the regulation of de novo ACE2 synthesis and its intracellular trafficking in normal and pathological conditions. Intracellular trafficking is a strictly regulated process, involving several steps which include interactions with specific proteins designated accessory proteins or molecular chaperones (Ciruela et al. 2010; Filipeanu 2015; Rodemer and Haucke 2008). ACE2-interacting proteins have not been investigated thus far and our group previously demonstrated that Ang-II induces ACE2 internalization and degradation into lysosomes through an $\mathrm{AT}_{1} \mathrm{R}$-mediated mechanism (Deshotels et al. 2014).

In the present work, we identify fascin- 1 as the only protein which in HEK293T cells has differential interactions with ACE2 after $4 \mathrm{~h}$ treatment with Ang-II, a time point that coincides with the lysosomal targeting of this enzyme (Deshotels et al. 2014). Fascin belongs to the large family of actin bundling proteins and has three different isoforms, fascin-2 being mostly expressed in retinal cells (Wada et al. 2001), fascin-3 only in testes (Adams 2004; Fagerberg et al. 2014), whereas fascin-1 is expressed ubiquitously but with 
greater extent in mesenchymal and nervous tissues (Jayo and Parsons 2010). Fascin-1 plays important roles in cell adhesion, migration, and neuronal growth cone morphogenesis and reorganization (Adams 2004; Gallop 2019; Wei et al. 2014). Phosphorylation of fascin-1 by protein kinase $C$ has been shown to abolish its actin bundling activity (Adams 2004; Jayo and Parsons 2010), whereas interactions of fascin-1 with Rac- and Rab35 GTP-ases were suggested to play a role in vesicular trafficking (Fagerberg et al. 2014; Parsons and Adams 2008; Zhang et al. 2009). Fascin-1 is overexpressed in many human cancers and its expression levels positively correlates with aggressive tumors (Jayo and Parsons 2010; Kulasingam and Diamandis 2013; Tan et al. 2013).

However, the present study shows that fascin- 1 can also play a role in the regulation of cardiovascular activity, particularly in regulating expression levels and subcellular localization of ACE2. Our results using proteomics, confocal microscopy, co-immunoprecipitation, and enzymatic activity demonstrate that fascin-1 interacts with ACE2. Importantly, when fascin-1 intracellular levels are increased, the effects of Ang-II on ACE2 internalization are greatly reduced (Fig. 3). In contrast, a decrease in fascin- 1 cellular levels leads to a major decline in ACE2 activity (Fig. 4), strongly suggesting that an optimal expression level of fascin-1 is required for maintaining the compensatory role of this enzyme against an overactive RAS. Even more interesting, we found that in the hypothalamus of DOCA-salt-induced hypertensive mice, a region known for harboring pre-sympathetic neurons involved in autonomic regulation (Mukerjee et al. 2019), the levels of fascin-1 were reduced. Cytoskeletal rearrangements by contractile stimuli in vascular smooth muscle cells have been reported (Ishida et al. 1999), and a decrease in fascin-1 cellular levels was observed in rapid ischemic neuronal response as well as in renal podocytes after mechanical stress (Kliewe et al. 2017; Meller et al. 2008). However, the present work is the first observation that fascin- 1 is decreased in chronic neurogenic hypertension. We propose that in normal conditions ACE2 is maintained to the plasma membrane through interactions with fascin-1, but in the presence of enhanced circulating Ang-II, these interactions are attenuated and the enzyme is internalized and degraded, a process that is enhanced in cells with reduced fascin-1 levels (Fig. 6), in agreement with our previous observations that ACE2 is reduced in this model (Xia et al. 2013).

Rearrangement of actin cytoskeleton has been shown to play important roles in intracellular traffic (Gallop 2019) and various proteins have been shown to specifically regulate the transport of receptors like tubulin for $\mathrm{AT}_{1} \mathrm{R}$ and $\alpha_{2 \mathrm{~B}^{-}}$ adrenergic receptors (Duvernay et al. 2011; Zhang et al. 2013), filamin A for somatostatin receptor type 2 (Treppiedi et al. 2019), and ERM proteins for tyrosine kinase receptors and viruses (Neisch and Fehon 2011). Our data reveal that

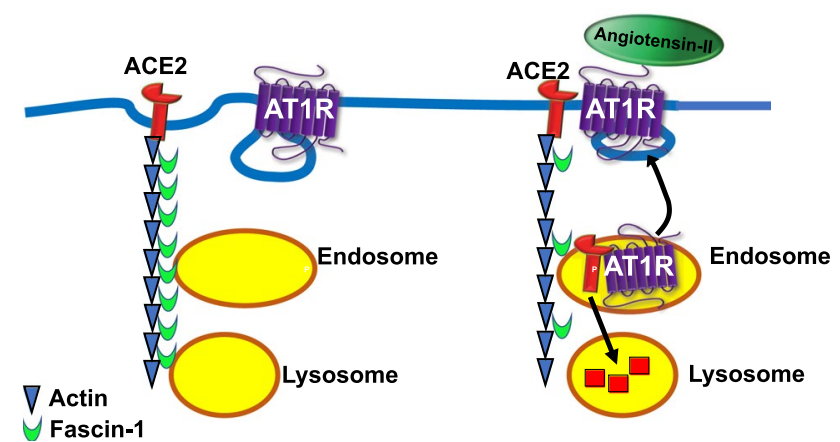

Fig. 6 Schematic diagram of the proposed involvement of fascin-1 in the regulation of ACE2 subcellular localization and expression levels. In normal conditions, fascin-1 binds to ACE2 and supports the enzyme localization to the plasma membrane (left). Increase in extracellular Ang-II concentrations leads to interactions between $\mathrm{AT}_{1} \mathrm{R}$ and ACE2 followed by internalization of the complex in endosomes, where it dissociates followed by $\mathrm{AT}_{1} \mathrm{R}$ recycling to the plasma membrane and the enzyme transport to lysosomes (Deshotels et al. 2014). In addition, decreases in fascin-1 cellular levels further contribute to ACE2 degradation (right)

beside the previously reported functions of fascin-1 (Adams 2004; Gallop 2019; Jayo and Parsons 2010), this actin bundling protein also mediates the traffic from plasma membrane to endo-lysosomal system. Whether or not this role is limited to ACE2 or fascin-1 may interfere with the traffic of other proteins remains to be determined.

In conclusion, we identified fascin-1 as an ACE2-accessory protein, interacting with the enzyme in an Ang-IIdependent manner. Moreover, fascin-1 expression levels represent an additional mechanism involved in the regulation of ACE2 activity and ultimately in the regulation of autonomic and cardiovascular functions.

Acknowledgements This work was supported by NIH R01HL15059201 Grant (to CMF and EL), COBRE Grant Number P30GM106392 (to EL and JJG), Merit Award (I01 BX004294) from the US Department of Veterans Affairs (to EL), and bridge funds from Howard University (to CMF).

\section{Compliance with Ethical Standards}

Conflict of interest All authors declare that they have no conflicts of interest.

\section{References}

Adams JC (2004) Roles of fascin in cell adhesion and motility. Curr Opin Cell Biol 16:590-596. https://doi.org/10.1016/j. ceb.2004.07.009

Bozgeyik I, Yumrutas O, Bozgeyik E (2017) MTUS1, a gene encoding angiotensin-II type 2 (AT2) receptor-interacting proteins, in health and disease, with special emphasis on its role in carcinogenesis. Gene 626:54-63. https://doi.org/10.1016/j.gene.2017.05.019 
Carvalho-Galvao A et al (2018) Central administration of TRV027 improves baroreflex sensitivity and vascular reactivity in spontaneously hypertensive rats. Clin Sci (Lond) 132:1513-1527. https://doi.org/10.1042/cs20180222

Ciruela $\mathrm{F}$ et al (2010) Adenosine receptors interacting proteins (ARIPs): behind the biology of adenosine signaling. Biochim Biophys Acta 1798:9-20. https://doi.org/10.1016/j.bbame m.2009.10.016

da Costa VG, Moreli ML, Saivish MV (2020) The emergence of SARS, MERS and novel SARS- 2 coronaviruses in the 21 st century. Archiv Virol. https://doi.org/10.1007/s00705-020-04628-0

de Queiroz TM, Xia H, Filipeanu CM, Braga VA, Lazartigues E (2015) alpha-Lipoic acid reduces neurogenic hypertension by blunting oxidative stress-mediated increase in ADAM17. Am J Physiol Heart Circ Physiol 309:H926-934. https://doi. org/10.1152/ajpheart.00259.2015

Deshotels MR, Xia H, Sriramula S, Lazartigues E, Filipeanu CM (2014) Angiotensin II mediates angiotensin converting enzyme type 2 internalization and degradation through an angiotensin II type I receptor-dependent mechanism. Hypertension 64:13681375. https://doi.org/10.1161/hypertensionaha.114.03743

Donoghue $\mathrm{M}$ et al (2000) A novel angiotensin-converting enzymerelated carboxypeptidase (ACE2) converts angiotensin I to angiotensin 1-9. Circ Res 87:E1-E9. https://doi.org/10.1161/01. res.87.5.e1

Duvernay MT, Wang H, Dong C, Guidry JJ, Sackett DL, Wu G (2011) Alpha2B-adrenergic receptor interaction with tubulin controls its transport from the endoplasmic reticulum to the cell surface. J Biol Chem 286:14080-14089. https://doi. org/10.1074/jbc.M111.222323

Fagerberg L et al (2014) Analysis of the human tissue-specific expression by genome-wide integration of transcriptomics and antibody-based proteomics. Mol Cell Proteomics 13:397-406. https://doi.org/10.1074/mcp.M113.035600

Feng Y et al (2010) Brain-selective overexpression of human angiotensin-converting enzyme type 2 attenuates neurogenic hypertension. Circ Res 106:373-382. https://doi.org/10.1161/CIRCR ESAHA.109.208645

Feng Y et al (2008) Angiotensin-converting enzyme 2 overexpression in the subfornical organ prevents the angiotensin II-mediated pressor and drinking responses and is associated with angiotensin II type 1 receptor downregulation. Circ Res 102:729-736. https://doi.org/10.1161/circresaha.107.169110

Filipeanu CM (2015) Temperature-sensitive intracellular traffic of Alpha2C-adrenergic receptor. Prog Mol Biol Transl Sci 132:245-265. https://doi.org/10.1016/bs.pmbts.2015.02.008

Filipeanu CM, Lazartigues E (2020) From cell surface to nucleus: Mas transportation in hypertension. Cardiovasc Res. https://doi. org/10.1093/cvr/cvaa087

Gallop JL (2019) Filopodia and their links with membrane traffic and cell adhesion. Semin Cell Dev Biol. https://doi.org/10.1016/j. semcdb.2019.11.017

Giannis D, Ziogas IA, Gianni P (2020) Coagulation disorders in coronavirus infected patients: COVID-19, SARS-CoV-1 MERS$\mathrm{CoV}$ and lessons from the past. J Clin Virol 127:104362. https ://doi.org/10.1016/j.jcv.2020.104362

Ishida T, Ishida M, Suero J, Takahashi M, Berk BC (1999) Agoniststimulated cytoskeletal reorganization and signal transduction at focal adhesions in vascular smooth muscle cells require c-Src. $\mathbf{J}$ Clin Invest 103:789-797. https://doi.org/10.1172/jci4189

Jayo A, Parsons M (2010) Fascin: a key regulator of cytoskeletal dynamics. Int J Biochem Cell Biol 42:1614-1617. https://doi. org/10.1016/j.biocel.2010.06.019

Karnik SS, Singh KD, Tirupula K, Unal H (2017) Significance of angiotensin 1-7 coupling with MAS1 receptor and other GPCRs to the renin-angiotensin system: IUPHAR Review 22. Br J Pharmacol 174:737-753. https://doi.org/10.1111/bph.13742

Kliewe F et al (2017) Studying the role of fascin-1 in mechanically stressed podocytes. Sci Rep 7:9916. https://doi.org/10.1038/s4159 8-017-10116-4

Kulasingam V, Diamandis EP (2013) Fascin-1 is a novel biomarker of aggressiveness in some carcinomas. BMC Med 11:53. https://doi. org/10.1186/1741-7015-11-53

Lopez-Ilasaca M, Liu X, Tamura K, Dzau VJ (2003) The angiotensin II type I receptor-associated protein, ATRAP, is a transmembrane protein and a modulator of angiotensin II signaling. Mol Biol Cell 14:5038-5050. https://doi.org/10.1091/mbc.e03-06-0383

Lucero HA, Kintsurashvili E, Marketou ME, Gavras H (2010) Cell signaling, internalization, and nuclear localization of the angiotensin converting enzyme in smooth muscle and endothelial cells. J Biol Chem 285:5555-5568. https://doi.org/10.1074/jbc. M109.074740

Meller R et al (2008) Ubiquitin-proteasome-mediated synaptic reorganization: a novel mechanism underlying rapid ischemic tolerance. J Neurosci. 28:50-59. https://doi.org/10.1523/jneur osci.3474-07.2008

Mendoza-Torres E et al (2018) Protection of the myocardium against ischemia/reperfusion injury by angiotensin-(1-9) through an AT2R and Akt-dependent mechanism. Pharmacol Res 135:112121. https://doi.org/10.1016/j.phrs.2018.07.022

Mukerjee S, Gao H, Xu J, Sato R, Zsombok A, Lazartigues E (2019) ACE2 and ADAM17 interaction regulates the activity of presympathetic. Neurons Hypertension 74:1181-1191. https://doi. org/10.1161/hypertensionaha.119.13133

Neisch AL, Fehon RG (2011) Ezrin, Radixin and Moesin: key regulators of membrane-cortex interactions and signaling. Curr Opin Cell Biol 23:377-382. https://doi.org/10.1016/j.ceb.2011.04.011

Ocaranza MP, Michea L, Chiong M, Lagos CF, Lavandero S, Jalil JE (2014) Recent insights and therapeutic perspectives of angiotensin-(1-9) in the cardiovascular system. Clin Sci (Lond) 127:549 557. https://doi.org/10.1042/cs20130449

Parsons M, Adams JC (2008) Rac regulates the interaction of fascin with protein kinase C in cell migration. J Cell Sci 121:2805-2813. https://doi.org/10.1242/jcs.022509

Pedersen KB, Chodavarapu H, Porretta C, Robinson LK, Lazartigues E (2015) Dynamics of ADAM17-mediated shedding of ACE2 applied to pancreatic islets of male $\mathrm{db} / \mathrm{db}$. Mice Endocrinol 156:4411-4425. https://doi.org/10.1210/en.2015-1556

Petrosillo N, Viceconte G, Ergonul O, Ippolito G, Petersen E (2020) COVID-19, SARS and MERS: are they closely related? Clin Microbiol Infect. https://doi.org/10.1016/j.cmi.2020.03.026

Rodemer C, Haucke V (2008) Clathrin/AP-2-dependent endocytosis: a novel playground for the pharmacological toolbox? Handb Exp Pharmacol. https://doi.org/10.1007/978-3-540-72843-6_5

Sriramula S, Lazartigues E (2017) Kinin B1 receptor promotes neurogenic hypertension through activation of centrally mediated mechanisms. Hypertension 70:1122-1131. https://doi.org/10.1161/ hypertensionaha.117.09744

Tan VY, Lewis SJ, Adams JC, Martin RM (2013) Association of fascin-1 with mortality, disease progression and metastasis in carcinomas: a systematic review and meta-analysis. BMC Med 11:52. https://doi.org/10.1186/1741-7015-11-52

Treppiedi D et al (2019) Cytoskeleton protein Filamin A is required for efficient Somatostatin receptor type 2 internalization and recycling through Rab5 and Rab4 sorting endosomes in tumor somatotroph cells. Neuroendocrinology. https://doi.org/10.1159/000503791

Vickers $\mathrm{C}$ et al (2002) Hydrolysis of biological peptides by human angiotensin-converting enzyme-related carboxypeptidase. J Biol Chem 277:14838-14843

Wada Y, Abe T, Takeshita T, Sato H, Yanashima K, Tamai M (2001) Mutation of human retinal fascin gene (FSCN2) causes autosomal 
dominant retinitis pigmentosa. Invest Ophthalmol Vis Sci 42:2395-2400

Wei Z, Sun M, Liu X, Zhang J, Jin Y (2014) Rufy3, a protein specifically expressed in neurons, interacts with actin-bundling protein Fascin to control the growth of axons. J Neurochem 130:678-692. https://doi.org/10.1111/jnc. 12740

Xia H, Feng Y, Obr TD, Hickman PJ, Lazartigues E (2009) Angiotensin II Type 1 receptor-mediated reduction of AngiotensinConverting Enzyme 2 activity in the brain impairs baroreflex function in hypertensive mice. Hypertension 53:210-216. https ://doi.org/10.1161/hypertensionaha.108.123844

Xia H, Sriramula S, Chhabra KH, Lazartigues E (2013) Brain angiotensin-converting enzyme type 2 shedding contributes to the development of neurogenic hypertension. Circ Res 113:1087-1096. https ://doi.org/10.1161/circresaha.113.301811

$\mathrm{Xu} \mathrm{J}$ et al (2017) Clinical relevance and role of neuronal AT1 receptors in ADAM17-mediated ace 2 shedding in neurogenic hypertension. Circ Res 121:43-55. https://doi.org/10.1161/circresaha .116 .310509
Xu P, Sriramula S, Lazartigues E (2011) ACE2/ANG-(1-7)/Mas pathway in the brain: the axis of good. Am J Physiol Regul Integr Comp Physiol 300:R804-R817. https://doi.org/10.1152/ajpre gu.00222.2010

Zhang J, Fonovic M, Suyama K, Bogyo M, Scott MP (2009) Rab35 controls actin bundling by recruiting fascin as an effector protein. Science 325:1250-1254. https://doi.org/10.1126/science.1174921

Zhang X, Wang H, Duvernay MT, Zhu S, Wu G (2013) The angiotensin II type 1 receptor C-terminal Lys residues interact with tubulin and modulate receptor export trafficking. PLoS ONE 8:e57805. https://doi.org/10.1371/journal.pone.0057805

Publisher's Note Springer Nature remains neutral with regard to jurisdictional claims in published maps and institutional affiliations. 